\title{
In Silico Analysis and Molecular Docking Studies of Plumbagin and Piperine Ligands as Potential Inhibitors of Alpha-Glucosidase Receptor
}

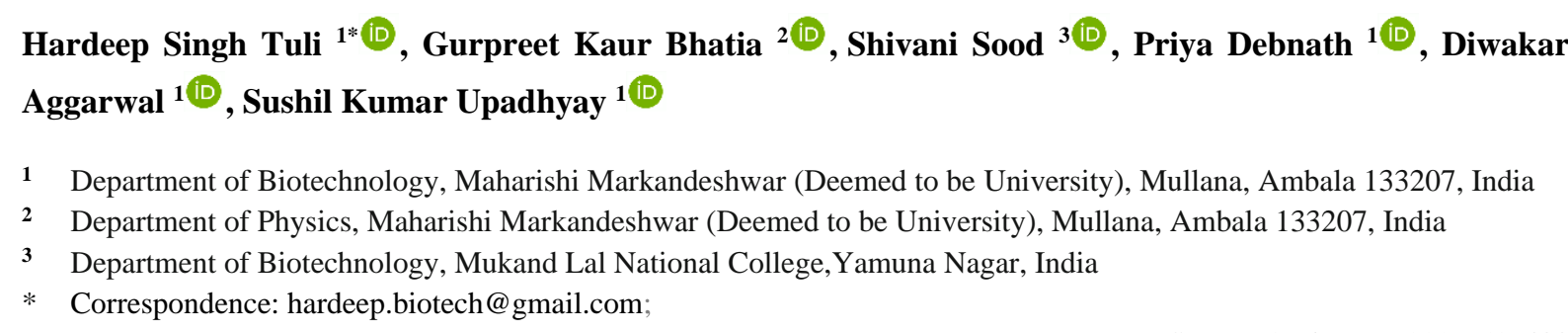

Scopus Author ID 55599516400

Received: 10.08.2020; Revised: 12.09.2020; Accepted: 14.09.2020; Published: 15.09.2020

\begin{abstract}
In 'today's generation, Diabetes mellitus is a very common lifestyle-based disease in which an insufficient amount of insulin is produced, which results in a rise of glucose level in the body with frequent urination and patient feels thirsty and hungry. In our present work, we have used the alphaglucosidase receptor against the natural plant product as a ligand for docking studies. For this in silico studies, various online tools, databases, and software were used. The proposed approaches were PDB, Molinspiration, Chemsketch, PyRx software, and many more. The binding scores were retrieved by PyRx software and no tumorigenicity, mutagenicity was there, and all parameters were in the desired range. The compounds used as ligands have shown energy minimization up to -6.7 to $-8.7 \mathrm{kcal}$ and can be further used as optimization, simulation, and in vitro and in vivo experimental validation.
\end{abstract}

Keywords: Diabetes mellitus; Molinspiration; Chemsketch; Tumerogenicity; Mutagenicity.

(C) 2020 by the authors. This article is an open-access article distributed under the terms and conditions of the Creative Commons Attribution (CC BY) license (https://creativecommons.org/licenses/by/4.0/).

\section{Introduction}

Enzymes play an important role in regulating a diverse range of biological and pharmacological processes of living beings. Enzyme inhibitory mechanisms are found to be associated with the treatment of various dreadful diseases such as cancer, cardiovascular, and neuro-degeneration. Therefore, enzyme inhibition has imperious utility in drug discovery and research [1-2]. $\alpha$-glucosidase is an enzyme released in the small intestine and known to regulate the process of absorption and digestion of carbohydrates. Evidence has suggested that $\alpha$ glucosidase can be targeted as a therapeutic drug target for diabetes mellitus and to control of sugar metabolism [3-6]. Recently, a variety of chemical inhibitors of glucosidase enzyme has been investigated. The major problems with chemical inhibitors are their associated side effects, such as colonic starch fermentation and abdominal discomfort (stomachache, diarrhea, and flatulence). These inhibitors have minimum effects on the body weight and are not recommended to the patients who have serum creatinine values greater than $2 \mathrm{mgdl}-1$ [7-8]. Therefore it has been essential to investigate natural therapeutic agents to inhibit the activity of glycosidase enzymes. The previous studies have demonstrated that natural therapeutic molecules are found to prevent cardiovascular, cancer, and other dreadful disease [9-15]. In view of the literature light, the present study was designed to investigate the 
promising role of phytochemicals (Plumbagin and Piperine) as binding ligand against alphaglucosidase. Plumbagin is a naphthoquinone derivative of the plant Plumbago zeylanica (Chitrak) and has hydroxyl groups in the $5^{\text {th }}$ position. It is a yellow color component from the black walnut drupe [16]. The other ligand, Piperine, is an alkaloid and $\mathrm{N}$ heterocyclic's derivative, which is mainly found in Piper nigrum (black pepper), a natural herb with promising medicinal value [17-19].

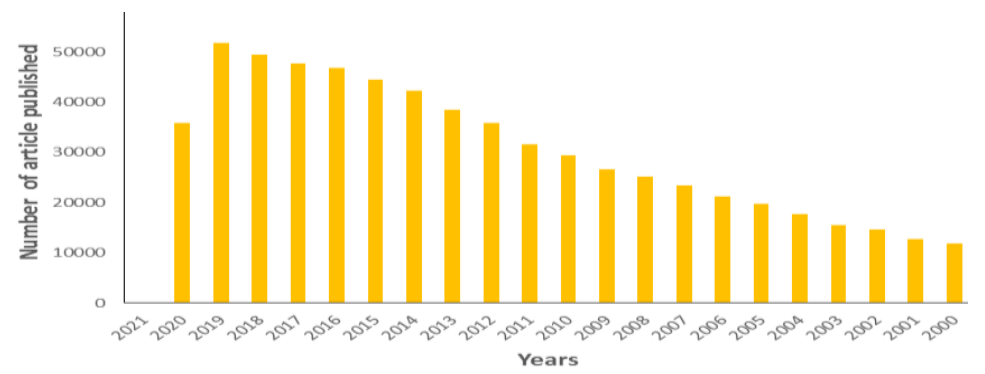

Figure 1. Graphical representation of year-wise investigation on the diabetic disease.

A search in PubMed NCBI using diabetes as a keyword has revealed that 35811 articles were registered up to August 4, 2020 (Fig. 1). The scientific community is still investigating the cure of this disease by doing intense research in this field. In silico computer-aided drug designing (CADD), it is considered an important tool to screen the possibility of interactions between a variety of ligands and proteins. Such studies do not only save the researcher's time but less time also cost-effective [20]. Drug designing strategies in docking studies to perform virtual screening of binding receptors of protein and ligand has been illustrated in Figure 2. Therefore the present study explored the utility of plant-based ligands to bind with glucosidase enzyme to slow down the carbohydrate digestion and absorption.

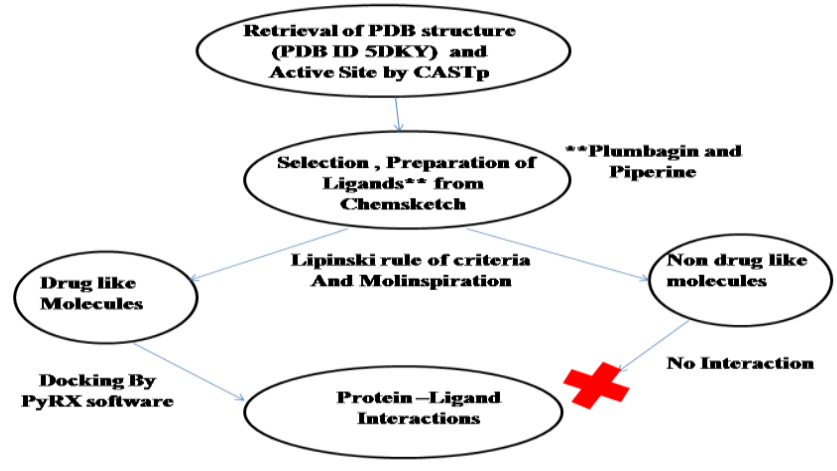

Figure 2. Methodology used in the docking studies.

\section{Materials and Methods}

In silico, Docking studies of Plumbagin and Piperine were performed using PyRX Autodock vina virtual screening tool, against the $\alpha$-glucosidase receptor in diabetes mellitus. Figure 2 depicts the flowchart study of methods used in this study.

\subsection{Structure retrieval of macromolecule and molecular visualization.}

Proteins are the macromolecules that have a long chain of amino acid residues. The three-dimensional structure of $\alpha$ glucosidase (PDB: 5DKY) was retrieved from the online server RCSB (http://www.rcsb.com) Protein Data Bank in its PDB format. The protein was prepared for docking study, and all water molecules were removed [21]. Figure 3 shows the 
3D structures of the alpha-glucosidase receptor protein. For the visualization of the 3-D structure of a protein, PyMol software was used. PyMol (www.pymol.org/) is open-source software for visualization and produce high quality of the 3-D image of protein molecules.

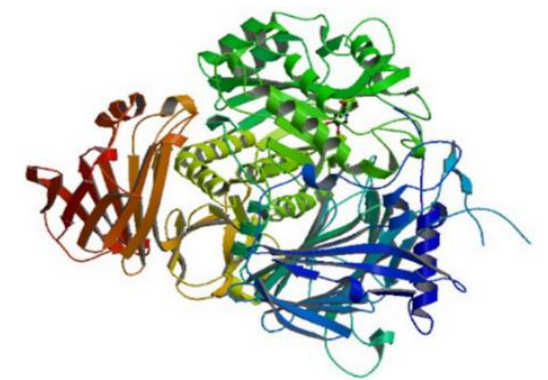

Figure 3. Structure of the receptor enzyme, $\alpha$-glucosidase; in this figure, $\beta$-sheets are represented in yellow, $\alpha$ helix are shown in red color, and the loop is indicated by green color. This is the representation of the receptor in cartoon structure.

\subsection{Prediction of the active site by CASTp (Computed Atlas of Surface Topography of proteins).}

The CASTp tool is a useful web-based method to predict the active site pockets and topology of $\alpha$ glucosidase [22]. The predicted sites are useful for determining and setting the grid box. The active sites with catalytic amino acids were further chosen for docking studies (Table 1.) and were analyzed using UniProt (http://www.uniprot.org/).

Table 1. Active pocket sites and their residue position of alpha-glucosidase were obtained from CASTp.

\begin{tabular}{|c|c|}
\hline Residue Positions & Amino acids \\
\hline $46-47$ & ARG \\
\hline 50 & ALA \\
\hline 51 & TYR \\
\hline 54 & HIS \\
\hline 61 & TRP \\
\hline 62 & GLU \\
\hline 64 & PRO \\
\hline 65 & TYR \\
\hline 85 & LYS \\
\hline 86 & THR \\
\hline 87 & ILE \\
\hline 88 & ASN \\
\hline 89 & ASP \\
\hline 90 & HIS \\
\hline 92 & GLU \\
\hline 94 & VAL \\
\hline 95 & ARG \\
\hline 114-115 & GLU \\
\hline 116 & LYS \\
\hline 203 & $\mathrm{ASN}$ \\
\hline 205 & GLU \\
\hline 206 & HIS \\
\hline 207 & TRP \\
\hline 208 & ARG \\
\hline 209 & PRO \\
\hline 210 & LYS \\
\hline 211 & ILE \\
\hline 212 & ASP \\
\hline $213-214$ & PRO \\
\hline $236-237$ & ASP \\
\hline 238 & SER \\
\hline 239 & THR \\
\hline $240-241$ & TRP \\
\hline
\end{tabular}




\subsection{Preparation of ligand structure.}

PubChem software consists of a chemical structure and biological information of chemical compounds. This software was used for ligands structure of Plumbagin and Piperine and saved in MOL SDF format for further interaction with receptors. The structure was further modified with the help of Marvin- Bean Package, which is illustrated in Figure 4.

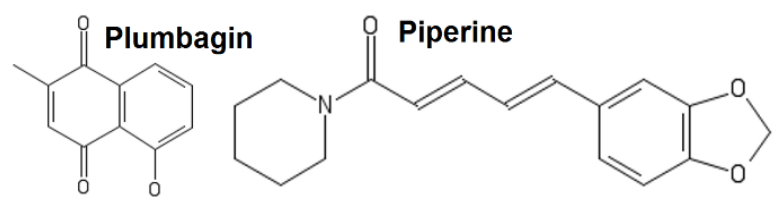

Figure 4. Ligand structure of Plumbagin and Piperine in two-dimensional form.

\subsection{Prediction of molecular properties and toxicity of ligands.}

The drug-likeness and molecular properties were calculated and screened by Mol inspiration [23], and 'Lipinski's rule of 5 [24]. The molecular properties of ligands Plumbagin and Piperine are in Table 2 that consists of molecular weight, $\log \mathrm{P}$, number of $\mathrm{H}_{2}$ bond acceptors, number of $\mathrm{H}_{2}$ bond donors, total surface area, rotatable bonds, tumorigenicity, mutagenicity, drug-likeness, etc.

Table 2. Molecular properties (Molinspiration and 'Lipinski's rule of five) and toxicity (OSIRIS Property Explorer) of ligands Plumbagin and Piperine.

\begin{tabular}{l|l|l} 
Properties & Plumbagin & Piperine \\
\hline Molecular Weight & 188.8 & 323.44 \\
\hline Log P & 1.78 & 4.05 \\
\hline Number Of Hydrogen Bond Acceptors & 3 & 3 \\
\hline Number Of Hydrogen Bond Donors & 1 & 0 \\
\hline Rotatable Bond Count & 0 & 6 \\
\hline Total Surface Area & 54.37 & 29.54 \\
\hline Volume & 163.16 & 319.24 \\
\hline GPCR ligand & -0.84 & 0.23 \\
\hline Ion channel modulator & -0.31 & 0.09 \\
\hline Kinase inhibitor & -0.57 & -0.25 \\
\hline Nuclear receptor ligand & -0.69 & -0.01 \\
\hline Protease inhibitor & -1.00 & -0.04 \\
\hline Enzyme inhibitor & 0.02 & 0.01 \\
\hline Mutagenic & Positive & Negative \\
\hline Tumerogenic & Negative & Negative \\
\hline Irritant & Negative & Negative \\
\hline Reproductive Effective & Positive & Positive \\
\hline Drug score & 0.21 & 0.29
\end{tabular}

\subsection{Molecular docking.}

In computational methods of CADD, virtual screening is very important and used to study molecules that bind to drug targets, protein receptors /or enzymes for interactions. In this study, PyRx (free) version was used to study the molecular docking. Default docking algorithms were used, and the $\mathrm{X}, \mathrm{Y}$, and $\mathrm{Z}$ coordinates were set in the grids and placed in active site pocket center, and the lowest binding energies were the best suitable for interactions [25].

\section{Results and Discussion}

Molecular docking is known to be very promising in identifying protein and drug interactions to discover hidden targets [26-27]. Evidence suggested that plant-based drugs are 
very useful for the treatment of many diseases [28]. In this study, plant-derived ligands were chosen to interact with $\alpha$ glucosidase, an enzyme known to regulate the metabolism of carbohydrates and insulin production [29]. The in silico analysis was carried out to analyze the potential of ligands Plumbagin and Piperine by using Lipinski's rule of five [30]. The molecular parameters were further verified over the Molinspiration server. Both the ligands passed the drug-likeness parameters.

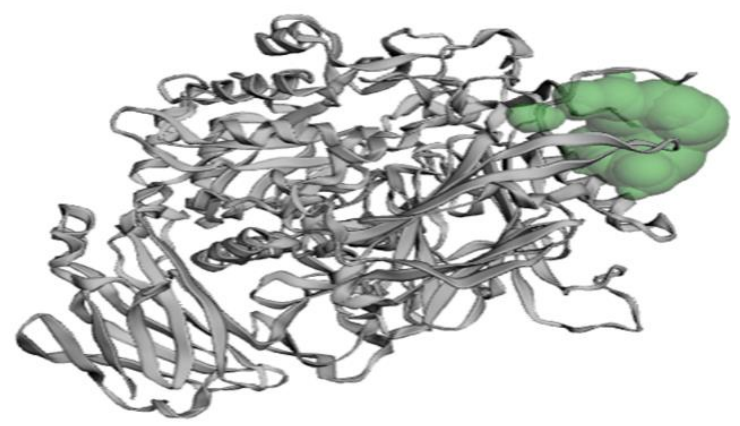

Figure 5. Prediction of pockets and ligand binding sites using CASTp of $\alpha$-Glucosidase protein.

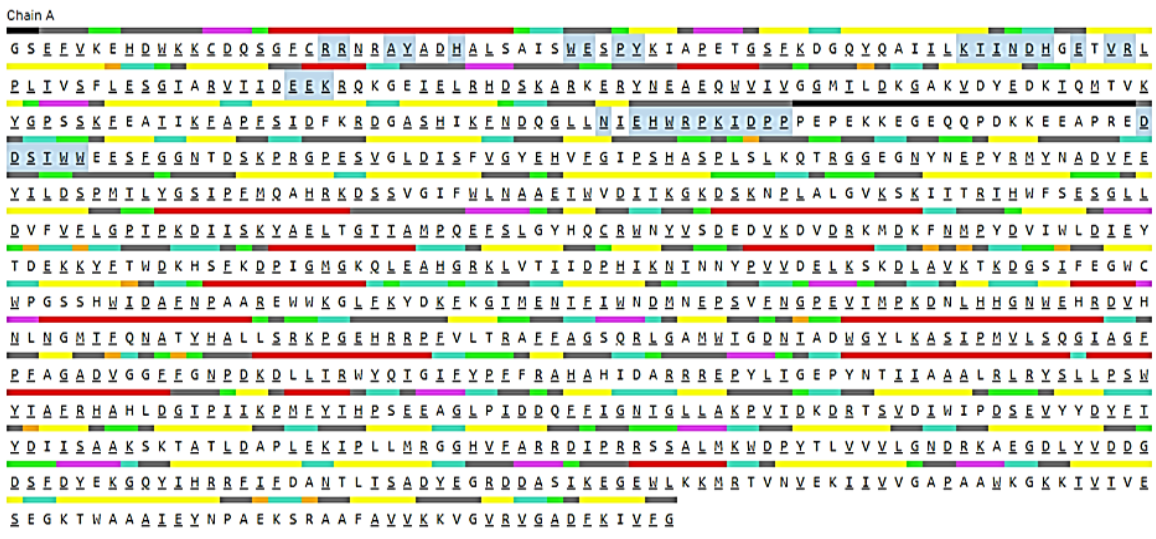

Figure 6. CASTp results of amino acids involved in forming an active site for alpha-glucosidase Letters highlighted in blue indicate active site residues.

Active sites were predicted by Castp and shown in Figure 5 and Figure 6 with residues name, amino acid position [31-32]. The receptor molecule has one Pocket id chain A with area 704.423 and 1094.106 surface/ volume area. The binding site positions were found at Chain A:303 ( Glucose, Mannose), Chain A: 443 (Glucose), Chain A: 617 (Glucose, Mannose), Chain A:633 (Glucose, Mannose), Chain A:691 (Glucose), and one disulfide linkage at position Chain A:39-45.

The inhibitory potential of the Plumbagin and Piperine can be studied by their binding energies (B.E) [33-34]. On docking, Plumbagin with $\alpha$-glucosidase has given the binding energy affinity of -6.7 , and other ligands Piperine possessed - $8.7 \mathrm{kcal}$ [35-36]. They both interacted with two amino acids of $\alpha$-glucosidase at GLY-228 and GLU-271. Table 3 represents the complete molecular docking results of ligands and receptor $\alpha$-glucosidase. Table 4 represents $\alpha$-glucosidase amino acids that are interacting with ligands and the distance between the interacting ligands poles to an amino acid. The docked pose of ligands and $\alpha$-glucosidase has been shown in Figure 7. Furthermore, the interaction between the amino acid of the receptor ( $\alpha$-glucosidase) and the active poles of the ligand Plumbagin i.e., ASN-301 and ARG-400 in this case, with the distance of $3.1 \AA$ and $3.0 \AA$ respectively, and: Piperine showed ASN-301 and 
ARG-400, with the distance of $3.1 \AA$ and $3.0 \AA$ respectively, which represents strong H-bonds [37].

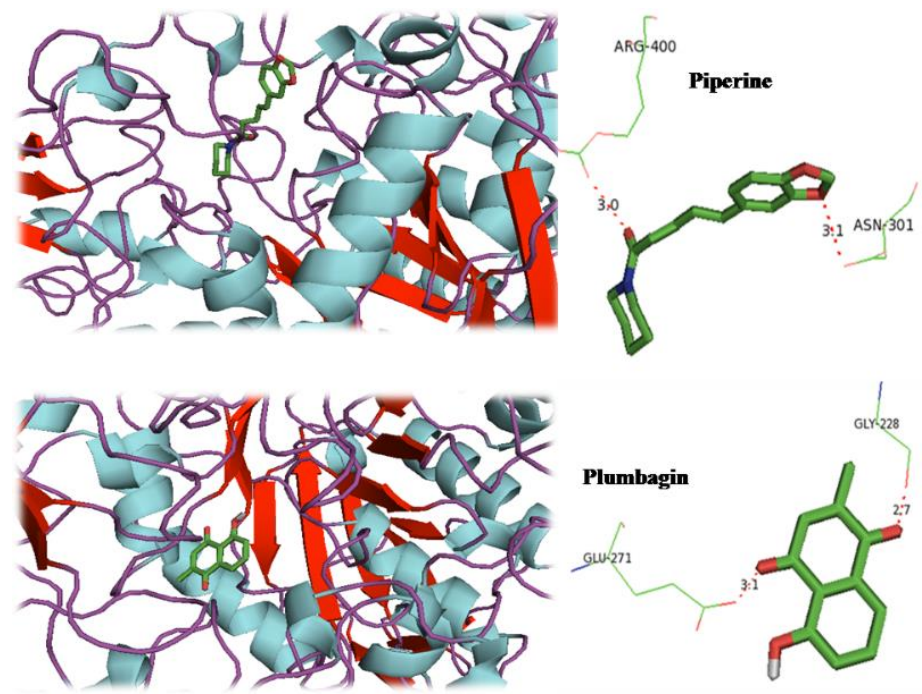

Figure 7. The docked pose of ligand (Piperine and Plumbagin) in the binding pocket of the enzyme, which is used as a receptor, $\alpha$-glucosidase. The ligand is shown in the stack structure, and the enzyme is shown in the cartoon model structure. This figure depicts the H-bond interaction between the ligand and blue dots show the $\mathrm{H}$-bonding between the ligand and the residue.

Table 3. Receptor and the ligand docked force field with their binding affinities at different positions and the best energy minimization with Piperine 8.7 and Plumbagin 6.7 as the lowest binding energy.

\begin{tabular}{c|c|c|c} 
Ligands & Receptors & Amino acid interacted & $\begin{array}{c}\text { Distance between the amino acid and the } \\
\text { ligand pole (̊) }\end{array}$ \\
\hline Piperine & $\alpha$-glucosidase & ASN-301 & 3.1 \\
& & ARG-400 & 3.0 \\
\hline Plumbagin & $\alpha$-glucosidase & GLY-288 & 2.7 \\
& & GLU-271 & 3.1
\end{tabular}

Therefore, lifestyle modification using bioactive phytochemicals may prevent diabetic diseases by regulating the activity of the glucosidase enzyme. The diagnosis rate of diabetes is very high. Therefore drug discovery strategies can further enhance by using computational approaches such as molecular docking. Such computational tools may not only minimize the experimental failure but also may help to design the molecular mechanisms of drug action. Another important aspect of molecular docking is to screen a large number of chemical drugs database for their interactions towards a particular protein.

Table 4. Interaction between the active poles of the ligands and the amino acid of the receptor ( $\alpha$-glucosidase).

\begin{tabular}{c|c|c|c|c|c|c|c}
\hline \multicolumn{1}{c}{ Piperine } & \multicolumn{3}{c}{ Plumbagin } \\
\hline & $\begin{array}{c}\text { Binding } \\
\text { Affinity }\end{array}$ & rmsd/ub & rmsd/lb & Ligand & $\begin{array}{c}\text { Binding } \\
\text { Affinity }\end{array}$ & rmsd/ub & rmsd/lb \\
\hline a-glucosidase_638024 & -8.7 & 0 & 0 & a-glucosidase_10205 & -6.7 & 0 & 0 \\
\hline a-glucosidase_638024 & -8.7 & 9.251 & 2.774 & a-glucosidase_10205 & -6.7 & 10.782 & 9.422 \\
\hline a-glucosidase_638024 & -8 & 1.873 & 1.112 & a-glucosidase_10205 & -6.4 & 10.685 & 9.113 \\
\hline a-glucosidase_638024 & -7.9 & 9.21 & 2.788 & a-glucosidase_10205 & -6.3 & 16.996 & 15.519 \\
\hline a-glucosidase_638024 & -7.8 & 9.514 & 3.041 & a-glucosidase_10205 & -6.3 & 17.547 & 15.698 \\
\hline a-glucosidase_638024 & -7.8 & 9.174 & 2.688 & a-glucosidase_10205 & -6.1 & 10.175 & 8.991 \\
\hline a-glucosidase_638024 & -7.7 & 9.003 & 2.797 & a-glucosidase_10205 & -5.9 & 1.873 & 1.25 \\
\hline a-glucosidase_638024 & -7.6 & 10.696 & 7.767 & a-glucosidase_10205 & -5.8 & 10.963 & 9.632 \\
\hline a-glucosidase_638024 & -7.6 & 9.551 & 2.936 & a-glucosidase_10205 & -5.8 & 11.28 & 10.064
\end{tabular}

Therefore in order to understand the interactions and binding affinities of ligands with glucosidase receptors, we performed molecular docking studies by using PyRx software. Previously also in silico studies of phytochemicals or their synthetic derivatives such as oriciacridone $\mathrm{F}$ and O-methylmahanineand 2-(benzo[d][1,3]dioxol-5-yl)-4H-chromen-4-one, 
respectively, have been carried to find $\alpha$-Glucosidase Inhibitors [38, 39]. It has been observed that the results of our study are comparable with previous research.

\section{Conclusions}

In the present study, the alpha-glucosidase was docked with ligands named Plumbagin and Piperine to calculate the binding energy and binding site to that of our target receptor. The results of the present study showed good binding site and docking value along with electrostatic, Vander Waals forces of attractions, and desolvation energies, which plays an important role in binding. These factors are considered for designing new inhibitors for $\alpha$ glucosidase. The ligands used in these studies had shown a good binding energy value with $\alpha$ glucosidase ranging from $-6.7 \mathrm{Kcal}$ to $-8.7 \mathrm{Kcal}$, which is acceptable for treating diabetes. Along with docking scores, the significant interactions of residues with the binding site were also observed. These in silico studies can be used in vitro studies as novel targets for designing anti-diabetic drugs and their mechanism studies.

\section{Funding}

This research received no external funding.

\section{Acknowledgments}

Authors are highly indebted to Prof. and Head, Department of Biotechnology, Maharishi Markandeshwar (Deemed to be University), Mullana for incessant encouragement during the research investigation.

\section{Conflicts of Interest}

The authors declare no conflict of interest.

\section{References}

1. Copeland, R.A. Evaluation of Enzyme Inhibitors in Drug Discovery: A Guide for Medicinal Chemists and Pharmacologists. $2^{\text {nd }}$ Edition; Wiley: Hoboken, New Jersey, United State of America, 2005; 46, 1-265.

2. Ghulam, A.; Zahid, H.; Ahmed, A.; Syed, A.; Ahood, J.; Zahra, K.; Ahmed, M. Synthesis, Molecular Docking, and Pharmacological Evaluation of Halobenzodithiophene Derivatives Against AlphaGlucosidase, Urease, and Free Radical Production. Turk. J. Chem. 2018, 42, 1113-1123.

3. Shimabukuro, M.; Tanaka, A.; Sata, M.; Dai, K.; Shibata, Y.; Inoue, Y.; Ikenaga, H.; Kishimoto, S.; Ogasawara, K.; Takashima, A.; Niki, T.; Arasaki, O.; Oshiro, K.; Mori, Y.; Ishihara, M.; Node, K. AlphaGlucosidase Inhibitor Miglitol Attenuates Glucose Fluctuation, Heart Rate Variability and Sympathetic Activity in Patients with Type 2 Diabetes and Acute Coronary Syndrome: A Multicenter Randomized Controlled (MACS) Study. Cardiovasc. Diabetol. 2017, 16, https://doi.org/10.1186/s12933-017-0571-1.

4. Saeed, A.; Shahzad, D.; Larik, F.A.; Channar, P.A.; Mehfooz, H.; Abbas, Q.; Hassan, M.; Raza, H.; Seo, S.Y.; Shabbir, G. Synthesis of 4-aryl-2, 6-dimethyl-3, 5-bis-N- (aryl)-carbamoyl-1, 4-dihydropyridines as Novel Skin Protecting and Anti-Aging Agents. Bangladesh J. Pharmacol. 2017, 12, 210-215, https://doi.org/10.3329/bjp.v12i2.32023.

5. Saeed, A.; Bosch, A.; Bettiol, M.; Gonzalez, D.L.N.; Erben, M.F.; Lamberti, Y. Novel Guanidine Compound against Multidrug-Resistant Cystic Fibrosis-Associated Bacterial Species. Molecules. 2018, 23, https://doi.org/10.3390/molecules23051158.

6. Patel, B.D.; Bhadada, S.V.; Ghate, M.D. Design, synthesis and Anti-Diabetic Activity of Triazolotriazine Derivatives as Dipeptidyl Peptidase-4 (DPP-4) Inhibitors. Bioorg. Chem. 2017, 72, 345-358, https://doi.org/10.1016/j.bioorg.2017.03.004.

7. Ghosh, S.; Collier, A. 'Churchill's Pocketbook of Diabetes. $2^{\text {nd }}$ edition; Churchill Livingstone, Edinburgh, New York, 2012; pp 1-344. 
8. Poude, P.; Griffiths, R.; Wong, V.W.; Arora, A.; Flack, J.R.; Khoo, C.L.; George, A. Oral Health Knowledge, Attitudes and Care Practices of People with Diabetes: A Systematic Review. BMC Public Health. 2018, 18, https://doi.org/10.1186/s12889-018-5485-7.

9. Kashyap, D.; Kumar, G.; Sharma, A.; Sak, K.; Tuli, H.S.; Mukherjee, T. Mechanistic Insight into CarnosolMediated Pharmacological Effects: Recent Trends And Advancements. Life Sci. 2017, 169, 27-36, https://doi.org/10.1016/j.lfs.2016.11.013.

10. Kashyap, D.; Sharma, A.; Sak, K.; Tuli, H.S.; Buttar, H.S.; Bishayee, A. Fisetin: A Bioactive Phytochemical with Potential for Cancer Prevention and Pharmacotherapy. Life Sci. 2018, 194, 75-87, https://doi.org/10.1016/j.lfs.2017.12.005.

11. Kashyap, D.; Sharma, A.; Tuli, H.S.; Sak, K.; Mukherjee, T.; Bishayee A. Molecular Targets Of Celastrol In Cancer: Recent Trends And Advancements. Crit. Rev. Oncol. Hematol.2018, 128, 70-81, https://doi.org/10.1016/j.critrevonc.2018.05.019.

12. Kashyap, D.; Garg, V.K.; Tuli, H.S.; Yerer, M.B.; Sak, K.; Sharma, A.K.; Kumar, M.; Aggarwal, V.; Sandhu, S.S. Fisetin and Quercetin: Promising Flavonoids with Chemopreventive Potential. Biomolecules. 2019, 9 , 174, https://doi.org/10.3390/biom9050174.

13. Aggarwal, V.; Kashyap, D.; Sak, K.; Tuli, H.S.; Jain, A.; Chaudhary, A.; Garg, V.K.; Sethi, G.; Yerer, M. B. Molecular Mechanisms of Action of Tocotrienols in Cancer: Recent Trends and Advancements. Int. J. Mol. Sci. 2019, 20, https://doi.org/10.3390/ijms20030656.

14. Tuli, H.S.; Tuorkey, M.J.; Thakral, F.; Sak, K.; Kumar, M.; Sharma, A.K.; Sharma, U.; Jain, A.; Aggarwal, V.; Bishayee, A. Molecular Mechanisms of Action of Genistein in Cancer: Recent Advances. Front. Pharmacol. 2019, 10, https://doi.org/10.3389/fphar.2019.01336.

15. Tuli, H.S.; Sharma, A.; Thakur, A. Natural Moieties as Anti-Inflammatory Agents-Recent Patents. Recent Pat Inflamm Allergy Drug Discov. 2019, 13, https://doi.org/10.2174/1872213X1302191122124225.

16. Kumar, A.R.; Merlin, N.J.; Arundhathi, R.P.; Dharan, S.S. In silico molecular docking evaluation of plumbagine derivatives for anticancer activity. J. Pharma. Sci. Res. 2019, 7, 2676-2678.

17. Ma, D.L.; Chan, D.S.; Leung, C.H. Molecular docking for virtual screening of natural product databases. Chem. Sci. 2011, 2, 1656-1665, https://doi.org/10.1039/C1SC00152C.

18. Ahmad, N.; Fazal, H.; Abbasi, B.H.; Farooq S, Ali, M.; Khan, M.A. Biological role of Piper nigrum L. (Black pepper): A review. Asian Pac. J. Trop. Biomed. 2012, 2, S1945-S1953, https://doi.org/10.1016/S2221-1691(12)60524-3.

19. Dhiman, P.; Malik, N.; Khatkar, A. Natural based piperine derivatives as potent monoamine oxidase inhibitors: An in silico ADMET analysis and molecular docking studies. BMC Chem. 2020, 12, 1-16, https://dx.doi.org/10.1186\%2Fs13065-020-0661-0.

20. Sarnpitaka, P.; Mujumdara, P.; Taylor, P.; Cross, M.; Costera, M.J.; Gorse, A.; Krasavin, M.; Hofmann, A. Panel docking of small-molecule libraries: prospects to improve efficiency of lead compound discovery. Biotechnol. Adv. 2015, 33, 941-947, https://doi.org/10.1016/j.biotechadv.2015.05.006.

21. Morris, G.M.; Huey, R.; Lindstrom, W.; Sanner, M.F.; Belew, R.K.; Goodsell, D.S.; Olson, A.J. AutoDock4 and AutoDockTools4: Automated docking with selective receptor flexibility. J. Comp. Chem. 2009, 30, 27852791, https://doi.org/10.1002/jcc.21256.

22. Dundas, J.; Ouyang, Z.; Tseng, J.; Binkowski, A.; Turpaz, Y.; Liang, J. CASTp: Computed atlas of surface topography of proteins with structural and topographical mapping of functionally annotated residues. Nucleic Acids Res. 2006, 34, W116-118, https://doi.org/10.1093/nar/gkl282.

23. Diebold, U. The surface science of titanium dioxide. Surf. Sci. Rep. 2003, 48, 53-229, https://doi.org/10.1016/S0167-5729(02)00100-0.

24. Lipinski, C.A.; Lombardo, F.; Dominy, B.W.; Feeney, P.J. Experimental and computational approaches to estimate solubility and permeability in drug discovery and development settings. Adv. Drug Deliv. Rev. 2001, 46, 3-26, https://doi.org/10.1016/s0169-409x(00)00129-0.

25. Trott, O.; Olson, A.J . AutoDock Vina: Improving the speed and accuracy of docking with a new scoring function, efficient optimization, and multithreading. J. Comp. Chem. 2010, 31, 455-461, https://doi.org/10.1002/jcc.21334.

26. Fatonah, A.; Tambunan, U.S.F.; Pamungkas, W.O.; Dewanto, G.L.; Wicaksono, I.S. Discovery of GPX4 inhibitor by molecular docking simulation as a potential ferroptosis inducer. Bioint. Res. Appl. Chem. 2020, 10, 4929-4933, https://doi.org/10.33263/BRIAC101.929933.

27. Tamer, K.K.; Abdelghany, A.M.; Kandil, E.M.; Elsefy, D.E.; El-Mekabaty, A. Hydroxyapatite/ZnCl 2 nanoflakes: An efficient catalyst for the synthesis of 2-arylbenzothiazoles with molecular docking and antioxidant evaluation. Bioint. Res. Appl. Chem. 2020, 10, 5182-5187, https://doi.org/10.33263/BRIAC102.182187.

28. Imran, S.; Sharma, V.; Tuli, H.S.; Aggarwal, D.; Sankhyan, A.; Vyas, p.; Sharma, A.K.; Bishayee, A. Cancer chemoprevention by flavonoids, dietary polyphenols and terpenoids. Bioint. Res. Appl. Chem. 2021, 11, 8502-8537, https://doi.org/10.33263/BRIAC111.85028537.

29. Heera, R.; Krishna, A. Improvements in insulin resistance and $\beta$-cells dysfunction by DDP-4 inhibition potential of Withania somnifera (L.) dunal root extract in Type 2 diabetic rat. Bioint. Res. Appl. Chem. 2021, 11, 8141-8155, https://doi.org/10.33263/BRIAC111.81418155. 
30. Aziz, M.H.; Dreckschmidt, N.E.; Verma, A.K. Plumbagin, a medicinal plant-derived naphthoquinone, is a novel inhibitor of the growth and invasion of hormone refractory prostate cancer. Cancer Res. 2008, 68, 9024-9032, https://doi.org/10.1158/0008-5472.CAN-08-2494.

31. Binkowski, T.A.; Naghibzadeh, S.; Liang, J. CASTp: Computed Atlas of Surface Topography of proteins. Nucleic Acids Res 2003, 31, 3352-3355, https://doi.org/10.1093/nar/gkg512.

32. Tian, W.; Chen, C.; Lei, X.; Zhao, J.; Liang, J. CASTp 3.0: computed atlas of surface topography of proteins. Nucleic Acids Res 2018, 46, W363-W367, https://doi.org/10.1093/nar/gky473.

33. Son, T.G.; Camandola, S.; Arumugam, T.V.; Cutler, R.G.; Telljohann, R.S.; Mughal, M.R.; Moore, T.A.; Luo, W.; Yu, Q.S.; Johnson, D.A.; Johnson, J.A. Plumbagin, a novel Nrf2/ARE activator, protects against cerebral ischemia. J neurochem 2010, 112, 1316-1326, https://doi.org/10.1111/j.1471-4159.2009.06552.x.

34. Osman, W.; Ismail, E.M.; Shantier, S.W.; Mohammed, M.S.; Mothana, R.A.; Muddathir, A.; Khalid, H.S. In silico Assessment of Potential Leads Identified from Bauhinia rufescens Lam. as $\alpha$-Glucosidase and $\alpha$ Amylase Inhibitors. J Pharmaceutical Res Int 2020,27-38, https://doi.org/10.1080/10799893.2020.1800734.

35. Sumsakul, W.; Plengsuriyakarn, T.; Na-Bangchang, K. Pharmacokinetics, toxicity, and cytochrome P450 modulatory activity of Plumbagin. BMC Pharmacol Toxicol 2016, 17, https://dx.doi.org/10.1186\%2Fs40360-016-0094-5.

36. Khelifi, I.; Hayouni, E.A.; Cazaux, S.; Ksouri, R.; Bouajila, J. Evaluation of in vitro biological activities: antioxidant; anti-inflammatory; anti-cholinesterase; anti-xanthine oxidase, anti-superoxyde dismutase, anti$\alpha$-glucosidase and cytotoxic of 19 bioflavonoids. Cellular and Molecular Biology (Noisy-le-Grand, France) 2020, 66, 9-19.

37. Jaitak, V. Molecular docking study of natural alkaloids as multi-targeted hedgehog pathway inhibitors in cancer stem cell therapy. Computational Biol Chem 2016, 62, 145-154, https://doi.org/10.1016/j.compbiolchem.2015.08.001.

38. Zafar, M.; Khan, H.; Rauf, A.; Khan, A.; Lodhi, M.A. In Silico Study of Alkaloids as $\alpha$-Glucosidase Inhibitors: Hope for the Discovery of Effective Lead Compounds. Front Endocrinol 2016, 7, https://doi.org/10.3389/fendo.2016.00153.

39. Meena, S.N.; Kumar, U.; Naik M.M.; Ghadi, S.C.; Tilve, S.G. $\alpha$-Glucosidase Inhibition Activity and in Silico Study of 2-(benzo[d][1,3]dioxol-5-yl)-4H-chromen-4-one, a Synthetic Derivative of Flavone. Bioorg Med Chem 2019, 27, 2340-2344, https://doi.org/10.1016/j.bmc.2018.12.021. 